\title{
Primeiras estórias: margens da história
}

\author{
Marli Fantini Scarpelli \\ Universidade Federal de Minas Gerais
}

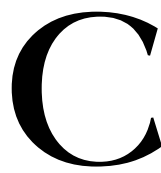

omprometido com a transformação do mundo, Guimarães Rosa acredita na potência da palavra criadora. Esta, no seu entendimento, guarda a capacidade de atualizar os sentidos e interferir na realidade cultural e histórica.

Seu texto reelabora a "estória" contra a "história", a alegre potência da palavra revitalizadora contra a hierarquia imobilizante e o status quo. O escritor mineiro demanda a renovação da língua, por meio da qual ele pretende injetar sangue novo no que se acha estagnado: "somente renovando a língua é que se pode renovar o mundo. Devemos conservar o sentido da vida, devolver-lhe esse sentido, vivendo com a língua". ${ }^{1}$ Não se trata, no entanto, do uso restritivo da língua vernácula ou da língua corrente:

Como escritor, não posso seguir a receita de Hollywood, segundo a qual é preciso sempre orientar-se pelo limite mais baixo do entendimento. Portanto, torno a repetir: não do ponto de vista filológico e sim do metafísico, no sertão fala-se a língua de Goethe, Dostoiévski e Flaubert, porque o sertão é o terreno da eternidade, da solidão, onde Inneres und Aussseres sind nicht mehr zu trennen, segundo o Westöstlicher Divan. ${ }^{2}$

\footnotetext{
${ }^{1}$ ROSA, 1994. p. 52.

2 As duas expressões citadas por Rosa em alemão são traduzidas pelo entrevistador no rodapé, seguindo a ordem em que elas aparecem na frase: "O interior e o exterior já não podem ser separados"; e O divã orientalocidental, uma das principais obras de Goethe. In: ROSA, 1994. p. 50.
} 
Guimarães Rosa investe, não apenas na capacidade renovadora da palavra, mas também nos mais variados usos da língua, para reconfigurar as representações estereotipadas de um universo cristalizado. Utilizando os princípios de "retradução intelectual", ele afina seus instrumentos para diluir a fronteira entre sanidade e loucura, corpo e território, tempo e espaço, local e universal, vida e arte, língua vernácula e língua estrangeira, história e estória, desencadeando o convívio tensionado de realidades que, sob a ótica do senso comum, seriam excludentes. Encenar, reengendrar, mesclar, por contágio e disseminação, distintas línguas e saberes faz parte do projeto literário com que o escritor mineiro investe no seu afã de renovar o mundo.

O neologismo "estória", não figurando então nos dicionários, aparece no título "Uma estória de amor", novela editada no conjunto do Corpo de baile, em 1956. O uso desse vocábulo na novela diz respeito ao acervo das narrativas provenientes da tradição oral e preservadas no sertão mineiro. Mas seu emprego se desdobra para representar uma nova forma de ler (e refazer) os fundamentos da "história". Em 1962, Guimarães Rosa publica Primeiras estórias, em cujo título figura novamente o neologismo. Prevendo especulações ou objeções conservadoras, Paulo Rónai (1969) faz este alerta, no prefácio do livro:

O epíteto não alude a trabalhos da mocidade ou anteriores aos já publicados em volumes, e sim à novidade do gênero adotado, à estória. Esse neologismo de sabor popular, adotado por número crescente de ficcionistas e críticos, embora ainda não registrado pelos dicionaristas, destina-se a absorver um dos significados de "história", o de "conto" (= short story). (...) Embora o termo, hoje em dia, já apareça também sem conotação folclórica, referido às narrativas de Guimarães Rosa envolve-se numa aura mágica, num halo de maravilhosa ingenuidade, que as torna visceralmente diferentes de quaisquer outras. ${ }^{3}$

${ }^{3}$ ROSA, 1969. p. 24. 
Luiz Costa Lima é provavelmente um dos primeiros críticos a reconhecer, no "planalto central", o suporte cênico para a fundação da "grande cidade" que cresce nos contos "As margens da alegria" e "Os cimos", respectivamente o da abertura e o do fecho de Primeiras estórias. No comentário a seguir, o crítico explicita a homologia entre a comunidade rosiana e a nova capital brasileira: "Modifica-se a realidade dos gerais e Guimarães Rosa anuncia a mudança. Brasília". ${ }^{4}$ Empenhado em ressaltar os resultados perversos do processo de modernização do Brasil, patenteados pelo desmatamento e desmantelamento do universo sertanejo, Guimarães Rosa estaria, segundo Costa Lima, incorporando à sua ficção as potencialidades do projeto de construção da nacionalidade brasileira: "Agora, porém, Guimarães Rosa nota que os seus gerais estão em mudança e, longe de tremer pela novidade, porfia por incorporá-la a seu universo". 5

Essa analogia não escapou à perspectiva crítica de Eneida Maria de Souza, que divisou "as figurações que bordejam o pensamento utópico", no lusco-fusco de um vagalume a iluminar uma passagem d' "As margens da alegria". ${ }^{6}$ Estabelecida a relação entre o cenário discursivo do conto e Brasília, Souza propõe uma reflexão sobre o colapso do imaginário utópico, salientando a importância das imagens que fulguram no texto rosiano "como forma de traduzir o imaginário utópico que momentos distintos da História e da Arte elegem como ensaios de redefinições de identidade". ${ }^{7}$

Em Tutaméia: terceiras estórias, obra publicada em 1967, poucos meses antes da morte de seu autor, consolida-se o sentido de "estória", a esta altura já consagrado na literatura rosiana. No primeiro dos quatro meta-prefácios dessa obra, a "estória", além de opor-se conceitualmente à "história", relaciona-se ao ideal de

\footnotetext{
${ }^{4}$ COUTINHO, 1991. p. 500.

${ }^{5}$ COUTINHO, 1991. p. 501.

${ }^{6}$ SOUZA, 1993. p. 154.

7 SOUZA, 1993. p. 147.
} 
concisão e agilidade da anedota, aproximando-se, dessa forma, da economia de meios própria à linguagem poética, na qual, cada vez mais, se ancora a prosa do escritor.

A estória não quer ser história. A estória, em rigor, deve ser contra a História. A estória, às vezes, quer-se um pouco parecida à anedota. A anedota, pela etimologia e para a finalidade, requer fechado ineditismo. Uma anedota é como o fósforo: riscado, deflagrada, foise a serventia. Mas sirva talvez ainda o outro emprego a já usada, qual mão de indução ou por exemplo instrumento de análise, nos tratos da poesia e da transcendência. ${ }^{8}$

Nesse texto, o escritor deixa patente a forma inesperada pela qual situações prosaicas podem conjugar-se com novos paradigmas históricos e estéticos. O concurso da metáfora renovante, ao dar sopro novo às formas cristalizadas, revela a aptidão para deslocar a mirada do sujeito da recepção e desencadear uma visão impactante e iluminada daquilo que via de regra é percebido de forma convencional.

Em sua entrevista a Lorenz, Guimarães Rosa fala do relacionamento familiar e amoroso que mantém com a língua. Sua expectativa é que os dois se afinem como "um casal de amantes que juntos procriam apaixonadamente", 9 e que, do triz de um atrito, possam gerar novas palavras, iluminando e ressignificando, ademais, as antigas. Essa relação amorosa é permeada da recorrente crença rosiana de que, para resistir ao próprio tempo, a linguagem deve ter todas as suas virtualidades semânticas, visuais e sonoras potencializadas em grau máximo de expressividade e ineditismo.

Contendo sua traduzibilidade na própria trama - matizada por múltiplas combinações de textura - o (meta)prefácio de Tutaméia propõe um pacto de abertura à doação de sentido, sob cujo impacto inovador o escritor espera provocar inúmeras e diferenciadas formas de recepção de sua obra. Guiadas por esse vetor, as "estórias" de Guimarães Rosa, seja pelo pacto amoroso, seja pelo pacto ficcional,

\footnotetext{
${ }^{8}$ ROSA, 1968. p. 3.

9 ROSA, 1994. p. 47.
} 
podem procriar e renovar-se, colocando-se a contrapelo do imobilizante continuum da história.

\section{Brasília: habitat padrão da modernidade}

No postulado hegeliano de que "o nosso tempo é um tempo de nascimento e de passagem para um novo período", ${ }^{10}$ Habermas nota o prenúncio do conceito de "arte moderna" expresso por Baudelaire. Este percebeu crítica e poeticamente as contradições entre a efemeridade e a imutabilidade já manifestas na arte de seu tempo. Nas palavras dele, "A modernidade [Modernität] é o transitório, o evanescente, o contingente, é uma metade da arte sendo a outra metade o eterno e o imutável". ${ }^{11}$

Tratando-se ainda de contradições e impasses da modernidade, Jeanne Marie Gagnebin registra que, no afã de "colonizar o futuro", a era moderna cultuou e, em simultâneo, desalojou o presente. A tensão capital da modernidade residiria, nesse sentido, na oscilação entre o perene e o provisório, em decorrência da qual apagou-se a linha de demarcação outrora tão clara entre o antigo e moderno. Gagnebin assinala que, ao se definir como "novidade", a modernidade adquire uma característica que, ao mesmo tempo, a constitui e a destrói”, o que a faz, de forma cada vez mais rápida, transformarse em seu contrário. ${ }^{12}$

Ancorada no ideal de funcionalidade do "habitat padrão", Brasília teve sua concepção arquitetônica norteada nos princípios universalistas da modernidade, cujo modelo, ditado pelas dogmas da "Carta de Atenas", de 1933, reconheceu em Le Corbusier seu maior divulgador. Segundo Guattari, esse modelo paradigmático de modernidade arquitetônica e urbana, credo teórico de várias gerações de urbanistas, "definitivamente terminou". Contra o modelo

\footnotetext{
${ }^{10}$ HABERMAS, 1990. p. 18.

${ }^{11}$ HABERMAS, 1990. p. 20.

${ }^{12}$ GAGNEBIN. Apud MACIEL, 1995. p. 180.
} 
encarnado no "habitat padrão", a contemporaneidade reclamaria, segundo o filósofo, por uma "cidade subjetiva", que engajasse tanto os níveis singulares da pessoa quanto os níveis mais coletivos. Dessa forma, "os urbanistas não poderão [afirma ele] mais se contentar em definir a cidade em termos de espacialidade". ${ }^{13}$

Em contraponto a Brasília, o modelo mais emblemático de modernidade arquitetônica brasileira, pode-se vislumbrar o afloramento do processo de modernização nas comunidades literárias de Guimarães Rosa, as quais, sob o vetor intersubjetivo, conjugam tradição e modernidade, coletividade e pessoalidade. Via de regra, nessas comunidades imaginadas, as demandas pessoais de subjetividade e desejo intervêm nas normas coletivas, para agenciar novas formas de interação sócio-cultural em similitude com o "plebiscito diário", expressão mediante a qual Renan postula os fundamentos basilares à constituição das nações modernas. ${ }^{14}$

\section{Cidade letrada}

Quando questiona o sentido renovador que norteou a fundação da nova capital brasileira, Mário Pedrosa recorda que, marcado a ferro e fogo pelo mesmo signo colonizador que condenou outros países da América Latina à uniformização e ao artificialismo, o Brasil é um país construído, um país feito, com data de nascimento precisa: 22 de abril de 1500. Diferentemente de outras nacionalidades americanas, "nunca tivemos passado, nem rastros dele por trás de nós", dotando-nos, portanto, do agravante de sermos "condenados ao moderno". Aqui não houve, por exemplo, as formidáveis vias de penetração dos velhos impérios, como o romano na Europa, e, às nossas costas, o inca. ${ }^{15}$ Nesse sentido, ao repetir o processo de transplante cultural do modelo ibérico que

\footnotetext{
${ }^{13}$ GUATTARI, 1992. p. 173-177.

${ }^{14}$ RENAN. Apud HOBSBAWN, 1990. p. 16.

15 PEDROSA, 1981. p. 305.
} 
presidiu à nossa colonização, o vetor moderno e renovador que orientou a concepção arquitetônica e urbana de Brasília, a "nova capital" brasileira, não passou de um malogro metafísico.

É sabido que a maciça política de transplantação do modelo cultural e estético vigente na Europa à época da colonização da América - o Barroco - condicionou as colônias, mal nascidas, a saltar do berço à civilização. Pedrosa argumenta que esse modelo artificial, destituído de organicidade, irá repetir-se em Brasília. De acordo com seu levantamento histórico, a artificialidade da nova capital federal encontra precedência no Egito, exemplo máximo de colônia articificialmente construída, cuja vida, "concentrada num oásis estreito, toma, ao chegar ao ponto, a forma disciplinada de uma cultura de viveiro". ${ }^{16}$ Insistindo na necessidade de que a cultura condicione sua existência à sua relação com a terra ("a cultura é a terra que o homem torna orgânica"), Pedrosa conclui que tal não ocorreu nem no Egito nem nas culturas americanas.

Num e noutro caso, se a cultura é artificial é porque lhe faltaram as resistências, os obstáculos naturais, sem os quais se engendra rapidamente um tipo uniforme e artificial. Num oásis, como é o caso do Egito, impõe-se uma disciplina civilizadora mediante a qual o natural é negar a natureza. É essa negação que, segundo Pedrosa, permite à nova cultura decidir e escolher as contribuições culturais que lhe convêm. Isso, contudo, não ocorreu na América, que já nasce sob o signo da modernidade.

O moderno vai sendo cada vez mais o nosso habitat natural. A América não era oásis entre desertos, era simplesmente nova: lugar onde se podia começar do começo. Os colonos (...) fizeram, então, tábula rasa, e, assim, puderam transplantar, por assim dizer, intatas suas formas culturais mais adiantadas, como se tratasse de uma transplantação para oásis. Sendo nova, sendo vasta, não havendo no seu solo senão a virgindade do mato e do solo (...), a América se fez com essas transplantações maciças de culturas vindas de fora:

${ }^{16}$ PEDROSA, 1981. p. 303-316. 
que estilo, que forma de arte foi imediatamente transplantada para o Brasil mal descoberto? A última, a mais "moderna" vigorante na Europa - o barroco. ${ }^{17}$

Tendo em vista o dificultoso implante de raízes capazes de gerar "brotos culturais autóctones", Pedrosa questiona a legitimidade da retomada do velho processo de "tomadas de posse" da terra. Por que, vencida a fase dos "oásis históricos" (o que possibilitaria a construção de uma história própria, a adaptação orgânica à terra e, desse modo, o assentamento "natural" da cultura), engendra-se a "engenhosa" idéia de criar a nova capital segundo paradigmas coloniais já suplantados?

Quer-se, então, fundar uma Capital ou plantar um novo oásis? Brasília participa ainda da concepção civilização-oásis. O novo oásis não é mais, evidentemente, uma estreita porção de terra entre desertos. (No entanto, as condições ecológicas dos pródromos da República, deixam bastante a desejar; as terras em volta da futura capital são áridas). ${ }^{18}$

Curiosamente, numa carta a Edoardo Bizzarri, ao elucidar dúvidas sobre o sentido do título "Campo geral”, Guimarães Rosa aproveita a oportunidade para relacionar a paisagem de Brasília à infértil aridez do cerrado. Na passagem em questão, a capital federal, contraposta às veredas (o oásis do cerrado), é ironicamente ilhada pelos "parêntesis" e se isola, inorgânica, do resto da paisagem. Autoreferente e auto-reguladora, a paisagem geopolítica de Brasília, tal como descrita por Rosa, comprime-se em uma árida metáfora que condensa, em seu fechamento, o meio e o fim de si mesma.

O que caracteriza esses GeraIs são as chapadas e os chapadões. São de terra péssima, vários tipos sobrepostos de arenito, terra infértil. (Brasília é uma típica chapada...).(...) A vegetação é a do cerrado, arvorezinhas tortas, baixas, enfezadas. (...) Mas, por entre as

\footnotetext{
${ }_{17}$ PEDROSA, 1981. p. 303-304.

${ }^{18}$ PEDROSA, 1981. p. 305-306.
} 
chapadas, separando-as há as veredas. (...) Nas veredas, há sempre o buriti. De longe, a gente avista os buritis, e já sabe: lá se encontra água. A vereda é um oásis. ${ }^{19}$

Em similitude às posições de Pedrosa, Ángel Rama entende o modelo da "cidade letrada" como a inscrição do sonho de uma ordem que encontrou, no novo continente descoberto e colonizado pela cristandade ibérica, o solo propício para sua transplantação. O crítico uruguaio denuncia que o princípio da tabula rasa, regido pela cegueira antropológica do colonizador, será determinante do modelo fundador das cidades americanas. Trata-se, para ele, de uma planta urbana desenhada a cordel y regla que translada o ideal ordenador da ideologia barroca para a colônia, seguindo-se as instruções reais aos conquistadores. No entendimento de Rama, a capital brasileira - projetada nas pranchetas de Lúcio Costa e Oscar Niemeyer - é o exemplo mais emblemático de cidade artificialmente planejada, com vista a encarnar, em seu traçado urbano, a forma de sua ordem social. ${ }^{20}$

$\mathrm{Na}$ conferência proferida durante o congresso intitulado "A cidade nova, síntese das artes", Mário Pedrosa estabelece a relação entre utopia e planificação, mas alerta que a colaboração entre arquitetos, escultores e pintores num esforço coletivo guiado pela liberdade criadora não foi suficiente para transformar Brasília em paradigma da "síntese das artes" (estéticas e políticas). O projeto moderno de construir, reconstruir e reordenar a geografia e a sociedade do mundo, vetor utópico da planificação da nova capital brasileira, é equacionado por Pedrosa.

Muito embora pautada no tema nuclear do congresso, "A cidade nova, síntese das artes"; no dilema identitário tributado à Novacap, ou seja, o de ser ou não ser o centro integrador de várias regiões do país; e ainda no reconhecimento de que a "nova capital" nasceu de uma política de planificação "com uma idéia coletiva,

\footnotetext{
${ }^{19}$ ROSA, 1981. p. 22-23.

${ }^{20}$ RAMA, 1985. p. 22.
} 
social e estética, mais alta, mais profunda mais ampla”, a conferência de Pedrosa converge para um outro eixo. Segundo o conferencista, trata-se, na verdade, de recolocar "o problema de uma reforma total, completa, humana, do centro do país", tributando à nova capital o papel político não de sintetizadora, mas de estabilizadora da frente de povoamento da região central do país. Concluindo, ele conclama os construtores de Brasília a empenhar-se no sentido de regionalizar o território central do país. Essa prática, ulterior aos fundamentos do "plano piloto", deveria, segundo ele, pautar-se num plano regional "talvez ainda mais importante que o plano urbanístico". ${ }^{21}$

Ao aceitarmos como premissa as reflexões de Pedrosa e Rama sobre a nova capital americana, não hesitamos em concluir que o falacioso pioneirismo em que se ancora o plano piloto de modernização acelerada do Brasil sustenta-se num malogro. Em outras palavras, quando pensávamos estar regionalizando e, portanto, inovando um país de tradição litorânea, vimo-nos reengendrando os fundamentos que regeram a política de implante cultural da máquina colonizadora. Além de reafirmar nossa dependência, essa repetição culmina no descaso político frente a problemas capitais ainda recorrentes no Brasil, tais como a desigualdade, a exploração e a depredação ambiental da região central deste país de tradição litorânea.

\section{As margens da modernidade}

Em diálogo insurgente com o plano piloto brasiliano, que, nas palavras de Rama, "é o mais fabuloso sonho de urbe de que foram capazes os americanos", ${ }^{22}$ as comunidades literárias de Guimarães Rosa, via de regra localizadas no sertão entre Minas e Goiás, tematizam o ingresso do Brasil no processo de modernização

\footnotetext{
${ }^{21}$ PEDROSA, 1981. p. 359-361.

${ }^{22}$ RAMA, 1985. p. 22.
} 
ocidental, sob o vetor intersubjetivo que conjuga arcaísmo e modernidade, comunitarismo e subjetividade, local e universal. No cruzamento alegórico entre história e representação literária, o processo de modernização do país, traçado nas linhas de fuga de um "móvel mundo", ${ }^{23}$ espacializa-se, nas narrativas do escritor mineiro, num âmbito regional que, quase sempre, faz fronteira com esferas mais amplas, continentais ou mesmo universais. Sob o efeito da transculturação, as comunidades literárias de Rosa afirmam-se, desde sua fundação, como emblema não da síntese apagadora de nossas diferenças regionais, mas da plasticidade espacial, histórica e cultural que caracteriza as heterogêneas regiões constitutivas do continente latino-americano.

Essa concepção recebe um de seus contornos n' "As margens da alegria", conto inaugural de Primeiras estórias, obra rosiana de 1962. Guiados pela ótica incontaminada de um "Menino", acompanhamos a irrupção de um novo mundo que, desde seu canteiro de obras, revela a intenção de inovar. Contudo, ao salientar as contradições da modernidade, o conto deixa inscritos, na morfologia arquitetônica da cidade em construção, os signos de uma posterior degradação. Pautada no questionamento sobre a inconclusão da modernidade ocidental e sobre o autoritarismo unificador que, sob a égide do "novo", deu suporte político ao projeto brasileiro de modernização, a estrutura desta narrativa torna patente a falibilidade da utopia sobre a qual nossa modernidade fragilmente erigiu seus fundamentos.

Assim, a leitura do conto não apenas aguça o olhar do leitor, fazendo-o debruçar-se criticamente sobre os limites da utopia que presidiu à aspiração brasileira de centralizar, em Brasília, o modelo de modernização do país. Um outro desafio é lançado a quem queira deslizar pelas margens que o conto deixa em aberto: tratase de manejar novas perspectivas ou dotar-se de uma "mirada estrábica”, conforme metáfora em que Ricardo Piglia se pauta para

${ }^{23}$ ROSA, 1964. p. 3. 
enfatizar a necessidade de intelectuais latino-americanos adotarem uma dupla posicionalidade para pronunciar seus pontos de vista: "há que se ter um olho posto na inteligência européia e outro posto nas entranhas da pátria”. ${ }^{24}$

De fato, trata-se de desafios que nos instigam a apreender as novidades oriundas do moderno cosmopolitismo europeu, sem deixar, contudo, de inter-relacioná-las às singularidades regionais de nossa cultura de origem. Se quisermos, entretanto, restringir-nos tãosomente aos conflitos nucleares da modernidade ocidental, podemos verificar que o conto desemboca no entrecruzamento do local com o universal para culminar no questionamento sobre os vetores mal digeridos pelas elites políticas, que foram responsáveis pelo processo de modernização do Brasil.

\section{Perenidade e efemeridade}

Dois eventos, paralelos e complementares, dão materialidade à permanente tensão entre o imutável e o contingente, a partir da qual o conto se abre à reflexão sobre os limites utópicos da modernidade. O primeiro deles é a construção de uma "grande cidade [que] apenas começava a fazer-se", na clareira de uma mata cerrada, num "semi-ermo, no chapadão". Como Brasília, a grande cidade é planejada sob os ícones do progresso e destina-se, a partir de uma projeção utópica, a ser "a mais levantada no mundo" .

O segundo evento, pondo em crise a expectativa gerada pelo primeiro, produz um efeito catastrófico nas certezas do "Menino" que protagoniza o conto. Trata-se do vislumbre de um peru imperial, cujo esplendor estético lhe acenara uma promessa de perenidade. O inesperado colapso das certezas, metaforizado na morte do peru, é responsável pela experiência de perda que coloca o protagonista em confronto com a consciência de que mesmo aquilo que é mais sólido desmancha no ar.

${ }^{24}$ PIGLIA, 1991. p. 61. Tradução minha. 
Diferentemente do "esplendor do concreto" da Brasília já construída, o conto representa uma espécie de "recenarização" dos primórdios da "Novacap" visto que o que aflora à visão do protagonista não é a "grande cidade", mas o seu canteiro de obras, um concentrado espaço de tensões, a partir do qual se pode divisar o permanente atrito entre a construção e a destruição. Nesse espaço aberto a transformações, surpreende-se a progressiva fratura de formas inteiras, dando visibilidade a um sombrio entre-lugar, um "hostil espaço" (AMA: 4), onde a projeção utópica vai sendo solapada pela implacável dissolução daquilo que, aos olhos desprevenidos do "Menino", se havia associado a plenitude e permanência.

A paisagem onde se planta a cidade é, portanto, uma zona de sombras onde confluem inovação e morte, natureza e cultura, rusticidade e modernidade. A difusa passagem de um para outro plano é entrevista pelo olhar cartográfico do "Menino" que, ainda inocente e sob o impacto da primeira viagem em avião, captura, num só flash, a fusão entre o campo de pouso e a provisória casa de madeira, cujo quintal se entremescla com a mata selvagem e aparentemente indevassável.

Exemplo dessa confluência pode ser observado no quase imperceptível deslizamento entre a rusticidade selvagem da natureza e a surpreendente tecnologia que pode ser divisada no avião a pousar numa clareira da mata. Esse trânsito só se torna discernível graças à à intervenção "cinematográfica" do narrador que, para dar acento ao contraste, adota a perspectiva do Menino, como se seu olho fosse uma "câmera" móvel e nervosa a registrar a contínua passagem entre os dois planos. Sob essa perspectiva, sugere-se uma inversão: a ameaça da natureza sobre a cultura.

O campo de pouso ficava a curta distância da casa-de madeira, sobre estações, quase penetrando na mata. O Menino via, vislumbrava (...). A morada era pequena, passava-se logo a cozinha, a ao que não era bem quintal, antes breve clareira, das árvores que não podem entrar dentro de casa. Altas, cipós e orquideazinhas amarelas delas se suspendiam. Dali, podiam sair índios, a onça, leão, lobos, caçadores? Só sons (ROSA, 1969: 4). 
Observa-se a crescente evidência de que a natureza, embora selvagem e hostil, não é incólume à brusca intervenção dos "pioneiros". Pragmática e provisoriamente voltados para a construção da cidade, estes parecem indiferentes à ameaça que seu gesto engendra. A desequilibrada troca entre natureza e cultura se mostra numa injusta contrapartida, visto esta destruir ostensivamente aquela, apesar de nela buscar os suportes necessários à própria existência.

A polarização de campos semânticos - de um lado, a ação de maquinarias destrutivas e mortais; de outro, a fragilidade das árvores, à mercê da bruta intervenção maquínica - endossa o contraste e autentica a posição crítica tacitamente desenhada na morfologia do conto. O trecho a seguir encerra a operação de trucidamento e destruição da mata, personificada aos olhos do Menino.

Ali fabricava-se o grande chão do aeroporto - transitavam no extenso as compressoras, caçambas, cilindros, o carneiro socando com seus dentes de pilão, as betumadoras. (...) Mostraram-lhe a derrubadora, que havia também: com à frente uma lâmina espessa, feito limpa-trilhos, à espécie de machado. (...) A coisa pôs-se em movimento. (...) A árvore, de poucos galhos no alto, fresca, de casca clara... e foi só o chofre: ruh... sobre o instante ela para lá se caiu, toda, toda. Trapeara tão bela. Sem nem se poder apanhar com os olhos o acertamento - o inaudito choque - o pulso da pancada. $\mathrm{O}$ Menino fez ascas. Olhou o céu - atônito de azul. Ele tremia. A árvore, que morrera tanto (ROSA, 1969: 6).

A interface de natureza e cultura, de arcaico e moderno duplica-se nessa zona nebulosa a partir da qual o protagonista do conto vive a dupla experiência de alumbramento e horror. Quando ainda visto do alto do avião, o "móvel mundo" parece uma linha harmoniosa e contínua a deslizar sem disjunções ou conflitos. A projeção do novo mundo de cima para baixo, no "chão plano em visão cartográfica”, é o mapa utópico que antecipa uma promessa de felicidade. Tão logo o avião aterrissa, a promessa, ainda não ameaçada, começa a cumprir-se quando o Menino se extasia ante a epifânica visão de um peru imperial, cuja perfeição estética ele acredita poder imobilizar. 
O peru, imperial, dava-lhe as costas para receber sua admiração (...) e ele completo, torneado, redondoso, todo em esferas e planos, com reflexos de verdes metais em azul-e-preto - o peru para sempre. Belo, belo! Tinha qualquer coisa de calor, poder e flor, um transbordamento. Sua ríspida grandeza tonitroante. Sua colorida empáfia. Satisfazia os olhos, era de se tocar trombeta (ROSA, 1969: 4).

Entretanto, a sensação de transbordamento, nova para ele, é subitamente reduzida à experiência de perda, quando o peru, no mesmo dia da descoberta, é morto para ser comido no almoço do dia seguinte. A evidente totemização encerrada nesse gesto faz da devoração do peru o signo da efemeridade do "novo", que, na sua novidade, já carrega a própria perecibilidade. Corroídas suas expectativas, o Menino "descobria o possível de outras adversidades, no mundo maquinal, no hostil espaço, e que entre o contentamento e desilusão, na balança infidelíssima, quase nada medeia”.

À cena da morte do peru, sobrepõe-se a da destruição da mata. Sem tempo para assimilar o novo impacto, o protagonista presencia a devoração dos despojos do peru antigo por um peru mais novo, destituído da exuberância imperial daquele. O deslizar metonímico entre essas cenas de igual valor simbólico patenteia o ritual de destruição que se mostra implicado na renovação. Na fração de minuto que dura o fulgor epifânico, o pensamentozinho do Menino, "ainda na fase hieroglífica", salta vários anos para fulgurar dilacerado nesta cartografia de sua alma: "Só no grão nulo de um minuto, o Menino recebia em si um miligrama de morte".

Não obstante, na série alegórica, instituída a partir do entrecruzamento de ficção com reflexão histórica e de um plano piloto autoritário com seu remanejamento estético, afora uma outra possibilidade - afirmativa e menor - de ler a modernidade e a história. O término do conto, em lugar de obscurecer, ilumina as margens para uma outra forma de utopia: uma utopia menor, que se acende quando toda a esperança parece desaparecer no meio da escuridão. A luz verde, mínima e intermitente de um vagalume, emergindo das trevas da mata agonizante, sinaliza - posto que provisória e melancolicamente - novas possibilidades de esperança e de alegria: 
Voava, porém, a luzinha verde, vindo mesmo da mata, o primeiro vagalume. Sim, era lindo! - tão pequenino no ar, um instante só, alto, distante, indo-se. Era outra vez em quando a alegria (ROSA, 1969: 7).

Ao traçar um roteiro alegórico onde se podem prever as conseqüências não mapeadas pelo "plano piloto" de Brasília, o conto "As margens da alegria" gera uma inversão. O forasteirismo encerrado na corrida para a "Novacap" transformou-a num grande acampamento onde se amontoaram os candangos, os primeiros a chegar para trabalhar nas obras, cujo término culminou no alijamento destes para a "cidade-satélite". Gravitando periférica no entorno da Capital Federal, esta se viu cada vez mais excluída dos privilégios desfrutados pelos políticos que logo tomaram posse da "Praça dos três poderes". Para culminar, à marcha dos candangos, seguiu-se a dos sem-terra que, emergidos dos miseráveis quadros sócioeconômicos disseminados pelos "gerais" do Brasil, desembocaram nos arrabaldes deste novo simulacro da "terra promissora".

Um dos maiores avatares do ideal de funcionalidade do "habitat padrão", Brasília acabou irônica e literalmente padronizada para se ajustar a toda sorte de heterogeneidades conflitivas que teve de abrigar. No ano dourado de 1960, a concorrida vernissage da nova capital do Brasil foi festejada por milhares de brasileiros comuns imiscuídos entre os convidados especiais vindos do mundo inteiro para ver de perto a realização da maior promessa utópica da modernidade brasileira e latino-americana. O que se assistiu, na transparência das fachadas de Brasília, foi, quase um século mais tarde, o revival dos "palácios de cristal" - um dos maiores emblemas da modernidade européia. E foi assim que a primeira edição de Primeiras estórias, de Guimarães Rosa, acontecendo dois anos depois da inauguração de Brasília, já vaticinava, em seu conto de abertura, o fim da utopia brasiliana. 


\section{Referências Bibliográficas}

GUATTARI, Félix. Caosmose: um novo paradigma estético. Trad. Ana Lúcia de Oliveira e Lúcia Cláudia Leão. Rio de Janeiro: Editora 34, 1992.

HABERMAS, Jürgen. O discurso filosófico da modernidade. Trad. Ana maria Bernardo et al. Lisboa: Publicações Dom Quixote, 1990.

HOBSBAWN, Eric J. Nações e nacionalismo desde 1780; programa, mito e realidade. trad. Maria Célia Paoli e Anna Maria Quirino. Rio de Janeiro: Paz e Terra, 1990.

LIMA, Luiz Costa. O mundo em perspectiva. In: COUTINHO, Eduardo F. (Org.). Guimarães Rosa. Rio de Janeiro: Civilização Brasileira, 1991.

MACIEL, Maria Esther. As vertigens da lucidez: poesia e crítica em Octavio Paz. São Paulo: Experimento, 1995.

PEDROSA, Mario. Dos murais de Portinari aos espaços de Brasília. São Paulo: Perspectiva, 1981.

PIGLIA, Ricardo. Memoria y tradición. Congresso ABRALIC (2: 1990: Belo Horizonte). Anais... v. 1. Belo Horizonte: UFMG, 1991.

RAMA, Ángel. A cidade das letras. Trad. Emir Sader. São Paulo: Brasiliense, 1985.

ROSA, João Guimarães. J. Guimarães Rosa: correspondência com seu tradutor italiano Edoardo Bizzarri. São Paulo: T. A. Queiroz editor, 1981.

ROSA, João Guimarães. Guimarães Rosa: ficção completa. 2 vol. Rio de Janeiro: Nova Aguilar, 1994. v. 1. Diálogo com Guimarães Rosa.

ROSA, João Guimarães. Primeiras estórias. Rio de Janeiro: José Olympio, 1969. As margens da alegria.

ROSA, João Guimarães. Tutaméia: terceiras estórias. Rio de Janeiro: José Olympio, 1968.

SOUZA, Eneida Maria de. Paisagens pós-utópicas. In: ANDRÉS, Aparecida (Org.). Utopias: sentidos Minas margens. Belo Horizonte: Editora UFMG, 1993. 


\section{Resumo}

"As margens da alegria", conto de abertura do livro Primeiras estórias encena, sob o signo da modernidade, a construção de uma "grande cidade" cujas bases utópicas serão examinadas em contraponto ao modelo de "cidades letradas", emblematizado por Brasília, a mais contraditória encarnação dos sonhos de utopia política da modernidade brasileira.

\section{Resumen}

"As margens da alegria", cuento que abre el libro Primeiras estórias escena, bajo el signo de la modernidad, la construcción de una "gran ciudad" cuyas bases utópicas serán examinadas en contrapunto al modelo de "ciudades letradas", emblematizado por Brasília, la más contradictoria encarnación de los sueños de utopía política de la modernidad brasileña. 